\title{
HUMOR Y CRÍTICA SOCIAL EN UN MODELO PARA ROSAURA
}

\author{
HUMOR AND SOCIAL CRITICISM \\ A MODEL FOR ROSAURA
}

\section{José Ángel Vargas Vargas*}

\section{RESUMEN}

En este artículo se realiza un análisis de la obra dramática Un modelo para Rosaura (1974) del escritor Samuel Rovinski Grusko (1934-2013). Como fundamento teórico se parte del concepto de la dramatización de lo inmediato, elaborado por este dramaturgo, así como de los aportes del crítico Lauro Zavala en torno al humor y a la ironía. Se efectúa una revisión de los mecanismos empleados por el autor para construir una imagen crítica de la clase media alta costarricense, abordando temas específicos como el matrimonio, la fidelidad, los modelos culturales y la relación entre lo nacional y lo extranjero. Lo anterior con el propósito de desestabilizar comportamientos sociales estereotipados y explorar las posibilidades de que el ser humano se asuma libre ante su entorno.

Palabras clave: Un modelo para Rosaura, Samuel Rovinski, drama costarricense, dramatización de lo inmediato, humor.

\begin{abstract}
**
This article develops an analysis about the dramatic play Un modelo para Rosaura (1974) by the writer Samuel Rovinski Grusko (1934-2013). The dramatization of the immediate element, a concept developed by this playwright, is taken as the theoretical basis, as well as the contributions made by the critic Lauro Zavala regarding humor and irony. A revision of the methods used by the author is carried out in order to build a critical illustration about the Costa Rican upper-middle class, dealing with specific topics such as marriage, faithfulness, cultural patterns and the connection between the natural and the foreign elements. All this with the purpose of destabilizing stereotyped social behaviors and exploring the possibility the human beings have to assume themselves free in their environment.

Key Words: Un modelo para Rosaura, Samuel Rovinski, Costa Rican theater, dramatization of the immediate element, humor.
\end{abstract}

Profesor catedrático de la Universidad de Costa Rica. Costa Rica. Doctor en Literatura por la Universidad de Salamanca.

** Traducción del resumen: Lic. Ana Patricia Quirós Cruz. Correo electrónico: JOSE.VARGASVARGAS@ucr.ac.cr Recepción: 22/10/13. Aceptación: 08/11/13. 


\section{Introducción}

Samuel Rovinski (1934-2013) ha sido uno de los pocos escritores costarricenses que por más de cincuenta años ha aportado sistemáticamente al desarrollo de la producción literaria y teatral costarricense. Desde 1960 con su obra La Atlántida hasta el 2006 con la publicación de Génesis se ha preocupado por ofrecer nuevos enfoques del arte y de la realidad por medio de sus obras, las cuales en gran medida responden a los diferentes procesos de desarrollo que ha experimentado la literatura en Costa Rica desde la segunda mitad del siglo anterior hasta la primera década de este siglo veintiuno. Virginia Sandoval considera que la obra de Rovinski lleva a la práctica avanzadas técnicas teatrales y se orienta en dos grandes direcciones: la farsa y el drama serio (Sandoval, 1987: 179-180).

Además de su fuerte vinculación con el teatro y la literatura, Rovinski ha colaborado con el desarrollo de la cultura nacional desde diversas trincheras: como profesor universitario, miembro del Consejo Universitario de la Universidad Nacional, miembro del Consejo Directivo de la Editorial Costa Rica, de la Compañía Nacional de Teatro y de la Orquesta Sinfónica Nacional y Presidente de la Asociación de Autores Costarricenses, entre otros cargos. También se ha distinguido por la búsqueda de formas específicas de representación del entorno social y de las aspiraciones del ser humano en determinadas circunstancias, de modo que su literatura ha generado un diálogo dinámico entre lo local, lo nacional y lo universal. Para ello, ha formulado su propia teoría de la dramatización de lo inmediato, en la que el componente retórico adquiere relevancia en la ficcionalización de distintas realidades, y además, le posibilita indagar sobre las conductas humanas.

Esta visión amplia de la producción teatral de Rovinski ha sido expresada, de manera muy sintética por el crítico Nicholas Rokas para quien "La preocupación central del teatro de Rovinski es el individuo con sus problemas existenciales de falta de realización personal y la supervivencia dentro de una sociedad en la que se ve victimizado por el abuso del poder político y militar, por las exigencias de una estructura social inflexible y por sus propias limitaciones" (Rokas, 1996: 214).

Esta afirmación de Rokas puede aplicarse, desde varias perspectivas, a cada una de las obras de este autor. Sin embargo, para efectos de esta ponencia, se ha seleccionado la obra Un modelo para Rosaura (1974) como principal objeto de estudio, con el propósito de observar el tipo de sociedad que se construye en ella, develar las particularidades del contexto social costarricense de la época y determinar la funcionalidad que cumple el humor como principal estrategia para cuestionar el orden social establecido. En un primer momento se expone la teoría de la dramatización de lo inmediato para luego abordar el modo como se construye una visión crítica de la sociedad, desde una perspectiva humorística. Finalmente, se presentan las respectivas conclusiones.

\section{Dramatización de lo inmediato como forma de representación de la realidad}

El proyecto fundamental de Rovinski a lo largo de su trayectoria como dramaturgo ha sido la de representar el comportamiento particular del ser humano ante las diferentes problemáticas de su realidad, lo cual lo ha llevado a elaborar su propia teoría de la "dramatización de lo inmediato" (Vargas y Vásquez, 1987:12), con el propósito de crear un teatro que tiene la misión ineludible de explorar y señalar la verdad de los acontecimientos sociales, de educar mientras entretiene, así como despertar genuinamente el espíritu crítico del público (Rovinski, 1980:25).

Esta definición constituye un replanteamiento de la responsabilidad social y cultural que le corresponde al autor, de modo que aparece como un sujeto inserto en los procesos sociales y políticos del entorno. Por ello, su producción textual no se genera en el vacío ni se constituye en un mero ejercicio escritural, por el contrario, logra articularse con 
diferentes contextos y le confiere a la obra una significativa dimensión social e histórica.

Esta teoría trasciende una mera reproducción de la vida en el texto o en el escenario, según corresponda, y propicia la posibilidad de que el espectador participe activamente del proceso semiótico, de tal forma que logre someter las acciones y los personajes a diferentes valoraciones, sin que ello implique la existencia de un teatro didáctico o comprometido con una sola causa ideológica. Sí pretende que el espectador se forme una posición crítica en relación con el espectáculo, con base en signos extraídos de la realidad cotidiana, los que a su vez se convierten en instrumentos de apoyo para la elaboración de un juicio sobre lo real.

Según el propio Rovinski, dramatizar lo inmediato implica asumir el acto creativo integralmente, con el propósito de que las acciones humanas sean representadas tanto en el ámbito individual como en el colectivo, reelaborando realidades concretas y míticas, comportamientos racionales y emotivos. Así lo explica el autor:

Esta consciencia de libertad de reunión en el teatro, para que los espectadores observen el reflejo crítico de lo cotidiano, obliga al dramaturgo a servirse del testimonio de lo inmediato para recrear, en el tiempo breve de una representación, la experiencia total del individuo, del grupo y del género humano, fundida en la inmediatez de la realidad y la ilusión, el mito y la historia, el sentimiento y la razón (Rovinski, 1998).

Desde esta perspectiva, la dramatización de lo inmediato conlleva la búsqueda de una participación libre del director y de los actores, de manera que el acto creativo permita reproducir los actos sociales e históricos y someterlos al criterio de los espectadores. Fiel a las teorías de otros dramaturgos, Rovinski le concede al espectador un lugar preponderante en el proceso de semiosis: "Como bien lo dijo Grotowski, innegable seguidor de las enseñanzas de Meyerhold, «el espectáculo no es una sumisión sino una reacción, y es esto lo que se llama crear"》 (Rovinski, 1998; también citado en Bolet, 1998:115).

La dramatización de lo inmediato requiere diferentes modos de representación de la realidad, por ello los contextos pueden ser reescritos desde formas genéricas tan disímiles como la tragedia y la comedia, las cuales a su vez están en función de lograr un efecto específico en los espectadores, que sin importar cuál sea este, los involucra en el mundo dramático que se construye y los lleva a conformar su propia posición ante la realidad que enfrentan o ante las aspiraciones que como seres humanos tienen.

\section{Humor y crítica social en $\boldsymbol{U} \boldsymbol{n}$ modelo para Rosaura}

Samuel Rovinski ha creado una obra dramática y teatral que se preocupa por el ser humano en sus múltiples facetas, de ahí que en ella aparezcan temas de diferente índole en los que se logra captar un diálogo entre lo universal y lo particular, lo cotidiano y lo trascendente, la ciudad y el campo, lo cómico y lo trágico. Todos estos aspectos se interrelacionan en diferente medida según las obras específicas, sin embargo, a lo largo de todas ellas hay un claro predominio del humor como forma retórica que lleva a un examen preciso de la realidad, incluso en El martirio del pastor, obra que mantiene un sentido trágico en toda la trama.

De acuerdo con lo señalado, el humor se ha constituido en uno de los principales rasgos de la obra de Rovinski, el que se aprecia desde sus primeras piezas, especialmente en Las fisgonas de Paso Ancho, de la cual el propio autor ha enfatizado que está llena de elementos humorísticos y que obedece a una observación externa de la vida del barrio, en la que se critican diversos actores de la sociedad. Esta forma de expresión de la realidad la ha mantenido en la mayoría de sus obras y posiblemente por esta razón, Virginia Sandoval (1987:181) ha afirmado que Rovinski se desenvuelve con mayor holgura en la comedia que en la tragedia.

Uno de los mayores méritos de Rovinski es que logra articular de una forma muy coherente su teoría de la dramatización de lo inmediato con el humor, la comedia y la risa. Para él, estos componentes deben ser el resultado de un acto 
creativo en el que se devela la función social del teatro, su referencialidad y su dimensión humana. Rovinski reconoce que para ello se ha fundamentado en Bergson:

\begin{abstract}
Bergson sostiene que no hay nada cómico fuera de lo propiamente humano y que para comprender la risa hay que reintegrarla a su medio natural, que es la sociedad, y determinar su función útil, que es una función social; o sea, que la risa debe tener una significación social. Nos dice que la comedia es un juego, un juego que imita a la vida y que es cómico todo arreglo de hechos y acontecimientos que, encajados unos en otros, nos den la ilusión de la vida y la sensación clara de un sueño mecánico (Rovinski, 1998).
\end{abstract}

Bergson asocia lo cómico al medio natural y a la sociedad, espacios en donde adquiere su verosimilitud. Sin embargo, lo cómico no constituye una actitud ingenua o aséptica porque tiene una función ideológica bien definida. A nivel retórico, el humor es un recurso que permite desestabilizar discursos estereotipados ya que los somete a unas reglas ficcionales que permiten cuestionarlos desde variadas perspectivas. Opera en unas coordenadas culturales específicas y según el teórico Lauro Zavala, constituye un disparador semántico que puede sustentarse en tres grandes categorías: el humor como mecanismo de relajación, el humor como forma de hostilidad (superioridad, agresión o malicia) y el humor como expresión de incongruencias (Zavala, 1993: 14-15).

En Un modelo para Rosaura se utiliza el humor como un mecanismo para realizar un fuerte cuestionamiento a la clase media alta costarricense, en sus conductas, aspiraciones y superficialidades. Sobre este particular, Rovinski ha afirmado:

\begin{abstract}
Hay en Un modelo para Rosaura una crítica de un modelo de vida en Costa Rica, sobre todo de la clase media alta y sus aspiraciones. Yo me he ganado muchos enemigos en Costa Rica; todos nos ganamos enemigos en la vida, pero tenía la suerte de ganarme enemigos muy bien colocados y entonces cada estreno de mi obra ha sido una polémica tremenda. (Rovinski, en Rokas, 1996: 224).
\end{abstract}

De acuerdo con Vega (2000:29), la clase media costarricense la han conformado los profesionales y técnicos, así como medianos empresarios y comerciantes, quienes con el crecimientodel empleoestatalylamodernización, lograron posicionarse en diversos ámbitos de la vida nacional. También en el periodo 19501980 el Estado incrementó las posibilidades de educación para todos los sectores, siendo la clase media alta muy favorecida, lo cual marcó un mayor acceso a los bienes simbólicos y también un fuerte consumismo de productos tanto nacionales como extranjeros. Estos factores le generaron grandes aspiraciones de educación y la ilusión de ser una clase culta. Cabe agregar que en las zonas rurales dicha clase creció significativamente gracias al dinamismo de la economía, al aumento de las exportaciones y a diversas actividades turísticas y financieras no tradicionales (Vega, 2000:44).

Rovinski examina esa clase social abordando temas como la cultura local y los modelos culturales, la educación, la relación del individuo con el medio, la búsqueda de nuevas formas de expresión, la fidelidad y el matrimonio, todos ellos elaborados de manera humorística. Así por ejemplo, Gerardo le ha prometido fidelidad y amor a Rosaura, a pesar de cualquier circunstancia como la pérdida de la belleza física por tener varios hijos. Rosaura lo ha cuestionado refiriéndose incluso al padre de Gerardo, de quien este no puede afirmar fehacientemente que haya sido fiel. El cuestionamiento mayor se produce cuando Gerardo, ante los reclamos de Rosaura, le pregunta que si ella le será fiel. Rosaura, con malicia y, buscando una igualdad, le responde con un tono irónico:

\section{GERARDO: Vos... ¿me serás fiel?}

ROSAURA: Tan fiel como vos (Rovinski, 1979: 221).

No solo el tema de la fidelidad se trata recurriendo al humor, ya que también los comportamientos asociados en términos generales a la clase media y al lenguaje que esta debe utilizar son objeto de un juego humorístico. Gerardo advierte que el lenguaje empleado por Rosaura no corresponde con la condición de una dama educada y de buenas costumbres y devela 
con jocosidad esa incongruencia. Así cuando Rosaura le manifiesta que es su novia y "no una puta", Gerardo reacciona indicándole: "Suena feo en tu boca. No es propia de tu condición" (p. 15). En este mismo sentido, Gerardo le presenta una visión muy positiva del matrimonio y del mundo "estable" de la finca, por lo que considera que debe ser definitivo. Rosaura muestra sus dudas, tanto en relación con la finca como con el matrimonio, a lo cual Gerardo le explica: "Una finca no es un cementerio. Ya te acostumbrarás y te gustará tanto que no querrás volver a la ciudad" (p.16).

En contraposición con el modo de pensar de Gerardo está Bobi, quien incita a su hermana Rosaura para que se atreva a no casarse y forjarse un mundo más abierto y auténtico. Rosaura vive una ambigüedad y duda porque lo prometido por Gerardo le produce cierta felicidad y además, no quiere contrariar a sus padres: "ROSAURA: ¿Dejarlo a estas alturas, con el ajuar traído de París, la iglesia y el Country reservados? Después de tu decisión de estudiar teatro le digo a mami que ya no me caso y, o me mata o se divorcia de papá" (p. 68).

La actitud de Bobi es cuestionar la superficialidad de lo material, de los modelos europeos (de vestidos y vehículos entre otros) ofrecidos por Gerardo, los cuales para él no representan la felicidad. Además, su opinión sobre el matrimonio es opuesta a los conceptos tradicionales que privan en su familia y en la de Gerardo, pues para él "la mayor parte del tiempo, marido y mujer son dos extraños ligados por deberes que deben cumplir por contrato establecido" (p. 69). Por eso le propone un cambio y lo hace con un sentido humorístico:

BOBI

Decía Confucio: "solamente el más sabio y el más estúpido no pueden cambiar".

ROSAURA

¿Y qué somos nosotros?

BOBI

No precisamente los más sabios...pero tampoco los más estúpidos. Simplemente que Confucio no vivió en nuestra sociedad (p. 70).
La incongruencia que se asocia al humor también se puede observar, cuando se abordan temas relacionados con la educación y la cultura, exponiendo a los personajes de tal forma que su pretendida cultura quede como algo falso y superficial. Tal es el caso de la visita de Doña Carmen, quien al escuchar la música expresa: “¡Pero qué linda música! Suena como a Kostelanetz", a lo cual de inmediato responde Rosaura evidenciando la equivocación: “Es Bach" (p. 27). Una situación semejante se presenta con la alusión que Doña Carmen hace a los muebles, mostrándose muy conocedora de ellos, pero en realidad no tiene la certeza si son castellanos o si son imitaciones.

Estas formas humorísticas implican también utilizar una intencionalidad irónica con la que se critica el comportamiento de los costarricenses, quienes son presentados como artificiosos e incapaces de transformar positivamente el país. Es Bobi el personaje que libremente logra expresar esa crítica al país en general y burlarse tanto de Gerardo, como de su padre:

BOBI: En este país están sucediendo cosas serias: invasión de los rusos, la oposición no se pone de acuerdo en nombrar un candidato, el encarecimiento de las joyas, la contaminación atmosférica a causa de la boñiga. ¿Me podés creer, cowboy, que en este desgraciado país ya no se puede comprar ni un Mercedes 250S, la marca del bienestar económico? Mi pobre familia ha tenido que resignarse al Rambler. Solo papá, el playboy de esta comunidad, con su Alfa Romeo (Rovinski, 1979: 24)

Mediante las diferentes estrategias de humor presentes en la obra, Rovinski como un observador de la sociedad costarricense de las últimas tres décadas del siglo veinte, no se desliga de ella y apunta a una lectura desestabilizadora de los comportamientos sociales. De acuerdo con las palabras del autor, esta visión abarca otros campos y es muy representativa del contexto, pues "de 1975 a 1980 Costa Rica se convirtió en un centro de efervescencia política, hecho que tuvo importantes repercusiones en la creación artística y literaria, incluso a nivel de la música, la cual asumió en muchos casos una actitud contestataria ante los órdenes del poder (Rovinski, 1985: 61). 
El final de la obra evidencia la tensión del personaje Rosaura producto de sus conflictos con el matrimonio y sus gustos, y además, su miedo a cambiar. Bobi a motiva a aventurarse por nuevos caminos. Veamos los últimos parlamentos del drama:

\section{GERARDO}

Vamos Rosi.

ROSAURA

Entonces será el recuerdo... (Gerardo la fuerza salir). Te acompaño ya Jerry.

BOBI

Adiós, cowboy. Adiós Rosie... (Sale Gerardo y lo sigue Rosaura, quien se detiene un instante en la puerta para volver a mirar a Bobi).

ROSAURA

¿Seré una bella novia?

BOBI

Un modelo cardin. (Sale Rosaura) (p.125).

La referencia a un modelo Cardin en este fragmento connota el mundo europeo de la moda, cuya característica esencial es la sofisticación, la cual se contrapone al ambiente tosco y tranquilo de nuestro país. Así frente al Cardin, aparece la finca como metáfora del país, en donde los personajes, principalmente Gerardo, muestran satisfacción con el entorno en que viven, sin aspirar a un universo más dinámico, como sí sucede con Bobi: "GERARDO: Pues yo lo siento, Rosaura. No soy poeta. Vivo entre ganado. Hablo con campesinos. Quisiera decirte todo eso pero solo puedo decirte que te quiero. Procuraré demostrártelo cuando estemos casados" (p. 16).

Justamente es Bobi el personaje símbolo del cambio en la obra. Es él quien introduce la necesidad de que el ser humano, de que Rosaura tenga otras expectativas y horizontes. Lo manifestó mediante diversas formas discursivas, y no logró una respuesta asertiva de Rosaura y quizá por ello al final incorpora la moda, que a criterio de estudiosos como Stoetzel (citado por Schlüter, 1996:240) constituye una marca de distinción, individualismo y singularidad y por lo tanto, la posibilidad de acceder a otros mundos. Ahora bien, la referencia al mundo europeo, en el ámbito de la estructura dramática y de los deseos de los personajes solo constituye una orientación y no el único camino de realización del ser humano.

\section{Conclusión}

Para concluir, es pertinente resaltar el carácter dinámico y transformador de la dramaturgia y del teatro de Rovinski. No ha sido un teatro estático, que no evoluciona en el tiempo, fijado en una época y en unos valores contextuales, sino una producción cultural renovadora en la que el lector puede encontrar respuestas a sus aspiraciones. Nada más apropiado que las palabras del propio Rovinski para sintetizar esta evolución:

El teatro no solamente devuelve la mirada del
fenómeno social ni se queda en la didáctica de la
historia: el teatro coloca a los seres humanos en su
realidad, que es lo actual y concreto, y es también
el conocimiento del pasado, el planteamiento de
preguntas y la recreación de los mitos universales.
El teatro, considerado como el fenómeno de
compresión del tiempo y el espacio en un escenario,
puede ser, con sus imágenes sucesivas, noche a
noche, el mundo cambiante que transforma nuestras
vidas. Como la existencia, el teatro no puede ser
inmóvil. Y para que tenga su propia fisonomía,
debe sufrir cambios, como la sociedad que lo
engendra (Rovinski, 1985, p.63).

Arnoldo Mora sintetiza el aporte de Rovinski, por medio del humor, a la construcción de un teatro y de una sociedad más justa, afirmando que el teatro de Rovinski es el mejor "teatro de denuncia que se ha producido en nuestro medio. La risa de Rovinski es un pretexto, no un fin en sí misma" (Mora, citado por Champagne, 2010). En realidad Rovinski se sirve del humor para realizar una advertencia a la sociedad y procurar cambios concretos que favorezcan a los seres humanos, desde una perspectiva integral. 
En Un modelo para Rosaura Rovinski, mediante su teoría de la dramatización de lo inmediato y con el apoyo en una retórica que privilegia el humor, elabora una fuerte crítica social que cuestiona patrones culturales y códigos que han caracterizado la sociedad costarricense de la segunda mitad del siglo veinte. Es una sociedad que deja al descubierto sus contradicciones y que se debate entre los valores nacionales y la admiración por lo extranjero, que cómicamente es referido como modelo.

Con este abordaje crítico del contexto, Rovinski interpela a los lectores para que se cuestionan sobre la realidad histórica, como lo ha hecho en Las fisgonas de Paso Ancho, Vispera del sábado, Gobierno de Alcoba, Gulliver dormido y Génesis, pero sin desligarse de las aspiraciones individuales de los personajes y de la búsqueda de las mejores formas para que estos puedan alcanzar sus proyectos, como se aprecia en la conducta de Bobi, quien se rebela contra el mundo establecido. No sucede lo mismo con Rosaura quien se aferra a su situación y no se atreve a dar pasos que la podrían desestabilizar: "ROSAURA: Tengo miedo de cambiar, Bobi. Esto es lo más seguro" (p. 125).

En fin, la obra, además de explorar el contexto sociohistórico, indaga en la condición humana y existencialista, en la medida que pone a los actores frente a una situación que deben resolver, lo que conlleva asumir un proyecto y luchar por concretarlo. En este sentido la crítica del autor también se dirige a quienes no luchan por alcanzar sus ideales y proyectos, como se desprende de sus palabas: "Generalmente, los seres humanos no se enfrentan a ese proyecto; dejan que otros lo hagan por ellos. O le dan la espalda o se van marginados. Son los que no realizan su vida. Esa es la posición de Sartre y del existencialismo. Y yo estoy con esa posición" (Rovinski, en Rokas, 1996: 227).

\section{Nota}

1. Rovinski, Samuel. 1979. Un modelo para Rosaura. San José, Costa Rica, Editorial Costa Rica. A partir de esta cita, cada vez que se refiera esta obra, solo se indicará entre paréntesis el número de página. Los demás datos corresponden a esta edición.

\section{Bibliografía}

Bolet Rodríguez, Teresa. 1998. "Entrevista con Samuel Rovinski”, en Confluencia, 3(2): 111-116.

Castagnino, Raúl Héctor. 1974. Semiótica, ideología y teatro hispanoamericano contemporáneo. Buenos Aires, Argentina, Editorial Nova.

Champagne, Carole A. 2010. "El mensaje inmediato de una tragedia colectiva" en Istmo. Núm. 21, julio-diciembre.

Kowzan, Tadeusz. 1997. El signo y el teatro. Trad. M. del C. Bobes y Jesús G. Maestro. Madrid, Arco Libros.

Rokas, Nicholas W. 1996. "Rovinski y el teatro contemporáneo en Costa Rica", en Confluencia, 11(2): 213-232.

Rovinski, Samuel. 1979. Un modelo para Rosaura. 2 edic. San José, Costa Rica, Editorial Costa Rica.

Rovisnki, Samuel. 1980. "Dramatización de lo inmediato". En: Escena, Año 3, 2: 24-25.

Rovinski, Samuel. 1985. "El teatro y el cine contemporáneos de Costa Rica", en Confluencia, 1: 56-64.

Rovinski, Samuel. 1998. La dramatización de lo inmediato. Discurso de ingreso en la Academia Costarricense de la Lengua, San José de Costa Rica.

Rovinski, Samuel. 2007. Génesis. San José, Costa Rica, Editorial Costa Rica. 
Sandoval, Virginia. 1987. "Dramaturgia costarricense", en Revista Iberoamericana, LIII(138-139): 173-192.

Schlüter, Regina. 2008. "Del recato a la libertad. Moda y turismo femenino entre 1910 y 1960", en Revista Itinerarium, volumen 1, Departamento de Turismo e Patrimônio - Escola de Museologia Centro de Ciências Humanas e Sociais. Universidade Federal do Estado do Rio de Janeiro (UNIRIO).

Vargas, José Ángel y Vásquez, Magdalena. 1987. Las fisgonas de Paso Ancho y El martirio del pastor. Dos perspectivas de la obra dramática de Samuel Rovinski. San Ramón, Universidad de Costa Rica.

Vega Martínez, Mylena. 2000. "La clase media en transición: situación y perspectivas al finalizar el siglo veinte", en Ciencias Sociales 86-87: 27-46.

Zavala, Lauro. 1993. Humor, ironía y lectura. Las fronteras de la escritura literaria. México, D.F, Universidad Autónoma Metropolitana.

\section{(@) $\mathbb{\otimes \Theta \Theta}$}

Este obra está bajo una licencia de Creative Commons

Reconocimiento-NoComercial-SinObraDerivada 4.0 Internacional. 